\title{
Superficial Temporal Vein
}

National Cancer Institute

\section{Source}

National Cancer Institute. Superficial Temporal Vein. NCI Thesaurus. Code C52700.

A vein on the side of the head that merges with the internal maxillary vein to form the posterior facial vein. 